\title{
Peatland archives of Holocene climate variability
}

\section{Vihula Manor, Estonia, 17-20 May 2009}

\section{StePHen T. JACKSON}

Department of Botany and Program in Ecology, University of Wyoming, USA; Jackson@uwyo.edu

Paleoclimatology got its start with $19^{\text {th }}$ and early $20^{\text {th }}$-century studies of peatland stratigraphy in northern Europe by Steenstrup, Blytt, Sernander, von Post, and others. Peatlands, particularly ombrotrophic (usually Sphagnum-dominated) systems, continue to be an important archive for Holocene paleoclimatology, paleohydrology and biogeochemistry, due to their high sensitivity to climate variability and sub-decadal to sub-centennial temporal resolution over timespans ranging from the past few centuries to the entire Holocene. Recent advances in dating and methodology, together with new studies in Europe, Asia, the Americas and New Zealand, offer opportunities for international scientific coordination and synthesis of existing records, priority-setting for future studies, and integration with Earth System models and other paleo-archives.

To these ends, PAGES sponsored a workshop on "Peatland Archives of Holocene Climate Variability and Carbon Dynamics" at Vihula Manor in rural Estonia from 17-20 May 2009. The workshop, co-sponsored by INQUA, the US National Science Foundation, the Quaternary Research Association, and the University of Tartu, was organized by Stephen T. Jackson (University of Wyoming), Edgar Karofeld (University of Tartu), Robert K. Booth (Lehigh University), Dan Charman (University of Plymouth), and Bas van Geel (University of Amsterdam). The workshop was attended by 34 scientists from 15 countries in Europe, North and Central America, and Asia, and included $2 \frac{1}{2}$ days of discussions and a $1 / 2$-day field trip to a local peatland.

Plenary presentations centered on refinement and development of paleo- climate proxies (R.K. Booth, J. Nichols), challenges imposed by scale, sensitivity, and uncertainty estimation (D. Charman), high-resolution dating and ${ }^{14} \mathrm{C}$ wigglematching (B. van Geel, M. Blaauw), peatland carbon dynamics (D. Beilman), and comparison of peatland records with other archives (A. Korhola, B. van Geel) and with paleoclimate models (S. Harrison). Initial breakout sessions concentrated on carbon dynamics, proxy and chronology refinement, and forward modeling of peatland response to climate change, with a second breakout series focused on development of peatland-archive data networks, and integrating peatland records with other archives and with Earth System models.

Key findings and recommendations include:

- Peatland archives can provide sensitive records of hydrology and carbon dynamics with decadal to centennial precision across large reaches of the globe. Standard proxies (testate-amoebae, humification, macrofossils) are being complemented by emerging proxies (organic biomarkers, stable isotopes), each with strengths and weaknesses. Integration of multiple proxies will strengthen inferences and differentiate climate variables.

Application of all proxies will benefit from taphonomic and process-based studies and from increased replication.

Paleoclimatology will benefit from a network of high-resolution peatland records focusing on specific time-intervals (e.g., last millennium, mid-Holocene, last deglaciation).

Quantitative assessment of errors and uncertainties in proxies, age-models and inferences deserves increased attention.
Development of process-based models of peatland-system responses to climate change at timescales of years to centuries will provide a means for connecting with climate-model predictions in a forward-modeling context, and clarify mechanisms that drive peatland proxy variables.

Peatland archives comprise a store of information on past carbon dynamics and peatland responses and feedbacks to climate change. Synthesis of existing records can address questions concerning the role of peatlands in the global carbon cycle as sinks and sources.

Systematic integration of peatland records with those from other archives will be fruitful in differentiating climate variables and drivers, and in detecting changes at different temporal scales. An important but surmountable challenge is posed by chronological correlation among records.

Archival and research databases of peatland records are needed to support data synthesis and application.

International collaboration and coordination should target collection of new data from key regions and time periods. Research priorities should be in general accord with broader goals of the international Earth System history and paleoclimate communities.

Follow-up activities, including database development and synthesis, preparation of review papers, and additional workshops and working groups are underway to address these recommendations.

\section{Note}

For more information on the workshop, please see: http://www.lehigh.edu/ rkb205/ peatworkshop/

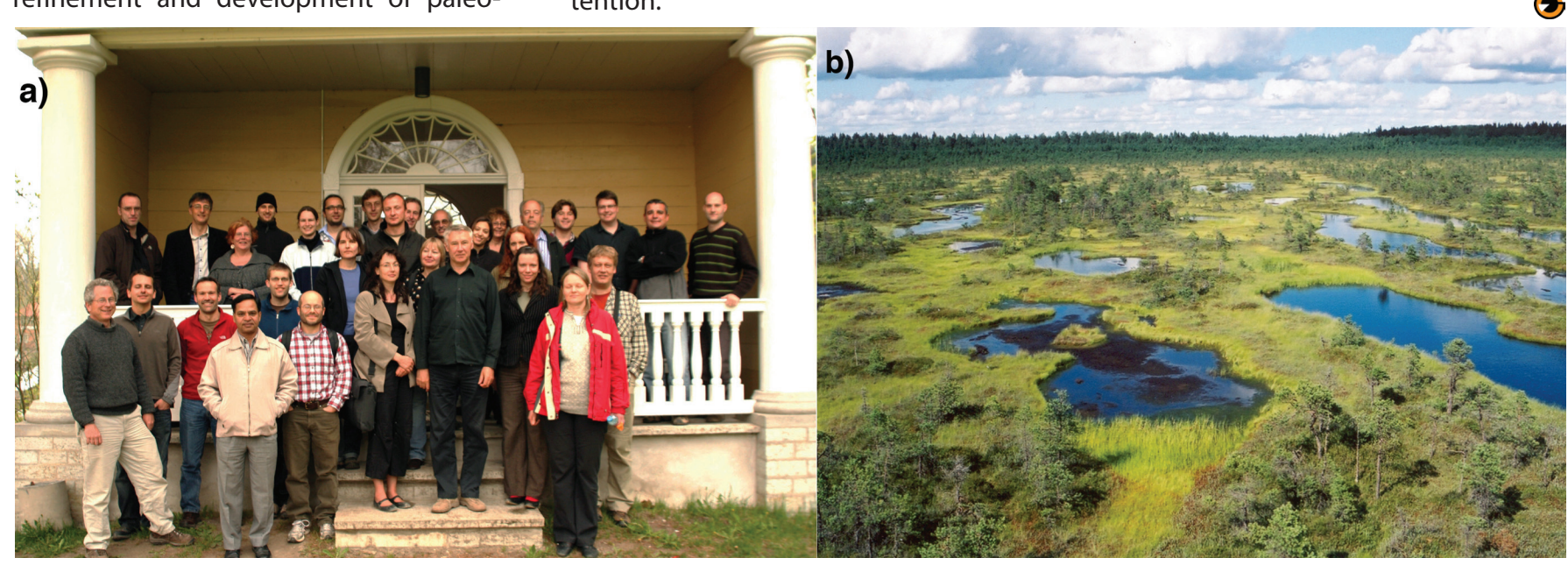

Figure 1: a) Photo of meeting participants (S. Jackson); b) Photo of Männikjärve Bog in central Estonia (E. Karofeld). 